\title{
Socio-cultural factors explaining timely and appropriate use of health facilities for degedege in south-eastern Tanzania
} Angel Dillip ${ }^{1,3}$, Manuel W Hetzel2 ${ }^{2}$ Dominic Gosoniu ${ }^{3}$, Flora Kessy ${ }^{1}$, Christian Lengeler ${ }^{3}$, Iddy Mayumana ${ }^{1}$, Christopher Mshana ${ }^{1}$, Hassan Mshinda ${ }^{5}$, Alexander Schulze ${ }^{4}$, Ahmed Makemba ${ }^{1}$, Constanze Pfeiffer ${ }^{3}$, Mitchell G Weiss ${ }^{3}$ and Brigit Obrist*3

\author{
Address: ${ }^{1}$ Ifakara Health Institute, Off Mlabani Passage PO Box 53, Ifakara, Morogoro, Tanzania, ${ }^{2}$ Papua New Guinea Institute of Medical Research \\ Goroka, EHP 441, Papua New Guinea, ${ }^{3}$ University of Basel, Swiss Tropical Institute, Socinstrasse 57, CH-4002, Basel, Switzerland, ${ }^{4}$ Novartis \\ Foundation for Sustainable Development, WRO-1002.11.56, CH-4002 Basel, Switzerland and ${ }^{5}$ Tanzania Commission for Science and \\ Technology, PO Box 4302, Dar es Salaam, Tanzania \\ Email: Angel Dillip - adillip@ihi.or.tz; Manuel W Hetzel - manuel.hetzel@pngimr.org.pg; Dominic Gosoniu - dominic.gosoniu@unibas.ch; \\ Flora Kessy - fkessy@ihi.or.tz; Christian Lengeler - christian.lengeler@unibas.ch; Iddy Mayumana - imayumana@ihi.or.tz; \\ Christopher Mshana - cmshana@ihi.or.tz; Hassan Mshinda - hmshinda@costech.or.tz; \\ Alexander Schulze - alexander.schulze@novartisfoundation.org; Ahmed Makemba -makemba_am@yahoo.co.uk; \\ Constanze Pfeiffer - constanze.pfeiffer@unibas.ch; Mitchell GWeiss - mitchell-g.weiss@unibas.ch; Brigit Obrist* - brigit.obrist@unibas.ch \\ * Corresponding author
}

Published: 29 June 2009

Malaria Journal 2009, 8:144 doi:10.1 I86/1475-2875-8-144
Received: 16 January 2009

Accepted: 29 June 2009

This article is available from: http://www.malariajournal.com/content/8/I/I44

(C) 2009 Dillip et al; licensee BioMed Central Ltd.

This is an Open Access article distributed under the terms of the Creative Commons Attribution License (http://creativecommons.org/licenses/by/2.0), which permits unrestricted use, distribution, and reproduction in any medium, provided the original work is properly cited.

\begin{abstract}
Background: Convulsions is one of the key signs of severe malaria among children under five years of age, potentially leading to serious complications or death. Several studies of care-seeking behaviour have revealed that local illness concepts linked to convulsions (referred to as degedege in Tanzanian Kiswahili) called for traditional treatment practices while modern treatment was preferred for common fevers. However, recent studies found that even children with convulsions were first brought to health facilities. This study integrated ethnographic and public health approaches in order to investigate this seemingly contradictory evidence. Carefully drawn random samples were used to maximize the representativity of the results.

Methods: The study used a cultural epidemiology approach and applied a locally adapted version of the Explanatory Model Interview Catalogue (EMIC), which ensures a comprehensive investigation of disease perception and treatment patterns. The tool was applied in three studies; i) the 2004 random sample cross-sectional community fever survey $(N=80)$, ii) the 2004-2006 longitudinal degedege study $(\mathrm{N}=129)$, and iii) the 2005 cohort study on fever during the main farming season ( $\mathrm{N}=29)$.

Results: $71.1 \%$ of all convulsion cases were brought to a health facility in time, i.e. within 24 hours after onset of first symptoms. This compares very favourably with a figure of $45.6 \%$ for mild fever cases in children. The patterns of distress associated with less timely health facility use and receipt of anti-malarials among children with degedege were generalized symptoms, rather than the typical symptoms of convulsions. Traditional and moral causes were associated with less timely health facility use and receipt of anti-malarials. However, the high rate of appropriate action indicates that these ideas were not so influential any more as in the past. Reasons given by caretakers who
\end{abstract}


administered anti-malarials to children without attending a health facility were either that facilities were out of stock, that they lacked money to pay for treatment, or that facilities did not provide diagnosis.

Conclusion: The findings from this sample from a highly malaria-endemic area give support to the more recent studies showing that children with convulsions are more likely to use health facilities than traditional practices. This study has identified health system and livelihood factors, rather than local understandings of symptoms and causes relating to degedege as limiting health-seeking behaviours. Improvements on the supply side and the demand side are necessary to ensure people's timely and appropriate treatment: Quality of care at health facilities needs to be improved by making diagnosis and provider compliance with treatment guidelines more accurate and therapies including drugs more available and affordable to communities. Treatment seeking needs to be facilitated by strengthening livelihoods including economic capabilities.

\section{Background}

Malaria continues to be a major public health problem worldwide and one of the leading causes of morbidity and mortality in sub-Saharan Africa, despite global and national control efforts. Malaria is one of the five lifethreatening conditions causing more than half a million deaths of African children annually [1]. In Tanzania, malaria is responsible for $34 \%$ of deaths among children under five years of age [2]. The global strategy for malaria control mainly focuses on case management, through early diagnosis and prompt treatment of all fever cases in malaria endemic areas [1]. Prompt diagnosis and timely malaria treatment within 24 hours after onset of first symptoms can reduce illness progression to severe stages, and therefore, decrease mortality.

Recent studies point out that before referral rectal artesunate can be given to patients who cannot be treated in time and are several hours away from facilities [3]. If patients cannot access injections or be treated orally, a single artesunate suppository at the time of the referral can reduce the risk of death or permanent disability. Nevertheless, the same multi-country trial showed that there was only a reduction of mortality of patients that were treated no later than six hours. Reaching clinics in time still remains crucial. However, prompt malaria treatment is a major challenge in many developing countries [4].

Before developing a partial immunity, children below five years of age in endemic countries are at a high risk of acquiring a severe form of malaria. Besides contributing to death, severe malaria amongst children under five years of age may cause serious complications, including brain damage and anaemia. The standard treatment of severe malaria is an intramuscular injection or an intravenous infusion of quinine [5].

Convulsions are one of the main manifestations of severe malaria. Several studies on childhood illnesses as reviewed by Williams and Jones [6] have provided contra- dictory evidence with regard to treatment of convulsions. Research in sub-Saharan Africa has revealed that conditions with convulsions as leading symptoms were not linked to malaria, and were primarily treated with traditional practices, as opposed to common fever cases for which modern biomedical treatment was preferred [712].

In Tanzania, the Kiswahili term used for convulsions in children is degedege. 'Degedege', meaning 'bird bird', is believed to be an evil spirit that takes form of a bird and casts its shadows on children who eventually become ill, develop convulsions and may die [13-15]. Fever cases are referred to as homa, and are commonly associated with malaria. Although the link between malaria and convulsions is recognized, degedege and homa tend to be treated differently. Degedege is reported more likely to be managed by traditional practices, while homa is mainly treated by the formal health system [14,16-19]. On the other hand, a study conducted in Kilosa and Handeni Districts in Tanzania [20] found that traditional healers encouraged modern treatment-seeking for convulsing children by referring severe cases of malaria to health facility. A recent study using verbal autopsy methodology indicated that $78.7 \%$ of malaria deaths in south-eastern Tanzania used modern treatment as the first resort to care [21]. Similarly, vignette interviews in Ghana revealed that more than $90 \%$ of respondents identified convulsions as severe conditions and recognized the need to seek modern treatment [22].

Some studies on the other hand showed that children with homa and/or degedege did not attend health facilities due to a number of access related factors, including availability and affordability of services [23-25]. Health service studies focus on health system factors and reducing supply barriers to ensure access to health care [26-28]. Such studies concentrate on improving the quality of care through ensuring availability of supplies, skilled staff, and quality of service [29]. 
The present study compared the local understanding and treatment of children under five years of age suffering from degedege with fever cases in rural areas of south-eastern Tanzania. Children under five years were selected because they are most at risk of contracting malaria. Within the study, interviews with caretakers (parents/ guardians) were conducted. The objective of the study was to describe and explain first treatment-seeking for degedege, and to explore how understanding of symptoms and causes related to degedege influence response strategies of care takers.

This study was conducted within the framework of the ACCESS Programme, a malaria intervention aiming at understanding and improving access to prompt and effective malaria treatment in rural Tanzania [4]. The study complements previous research [30] carried out within the same programme to investigate access obstacles to malaria treatment.

\section{Methods}

\section{Study area}

This study took place in the Kilombero and Ulanga Districts in Southeastern Tanzania. The research site is part of the local Health Demographic Surveillance System (HDSS) covering 25 villages in the two districts. The programme conducts its monitoring and evaluation activities through this HDSS. Every four months HDSS staff monitor and register all births, deaths, pregnancies, socio-economic indicators, and in- and out-migrations of all residents through household surveys [4]. This allows on one hand the tracking of all individuals and most importantly for this work, to draw an almost perfect random sample, which is essential for the representativity of the results. In 2004, the population of the 25 HDSS villages in Kilombero and Ulanga Districts was 74,200 inhabitants, with an additional 45,700 people living in Ifakara town, the main settlement in the districts [31].

In 2004 there were 14 public and private health facilities in the study area [4]. Moreover over 400 drug shops were present (general shops selling drugs: 454; shops stocking anti-malarials: 54); from 2006 onwards these included among which Accredited Drug Dispensing Outlets (ADDOs), which are allowed to sell a limited range of prescription-only medicine, and so-called Part II drug stores, which offer over-the-counter (OTC) drugs. General shops provide antipyretics, although in some villages they illegally dispense anti-malarials as well. There are many traditional healers providing varying kinds of services ranging from protection of disease, to treatment of illness and other misfortunes associated with witchcraft and spirits [13].
The most common activities are subsistence farming, fishing and small scale trading, with rice and maize being the predominant food crops. Families spend several months in their farming site (shamba in Kiswahili), located at an average $7.5 \mathrm{~km}$ away from the main houses in the fertile lower wetlands [32].

\section{Instruments}

The present study used a cultural epidemiology approach, and applied a locally adapted and constructed version of the Explanatory Model Interview Catalogue [33]. EMIC interviews allow for assessing specified health problems from the local perspective of affected individuals, their families, and/or community members [22]. The interviews aim to gather information on people's knowledge, understanding and experience of diseases such as malaria $[13,16]$. As a semi-structured interview, the EMIC was applied in the ACCESS Programme in order to collect both quantitative and qualitative information on illness experience, its meaning and related behaviour for fever and degedege, mostly referred to as patterns of distress (PD), perceived causes (PC) and help-seeking (HS) [33]. EMIC interviews extract explanatory models of respondents in their own terms [33] and explain how such models influence particular behaviors. For the purpose of this study, EMIC was employed to understand how explanatory models for degedege influence treatment-seeking behaviours.

\section{Study design}

A similar EMIC was applied in three different studies (for details see Table 1):

1. A random sample cross-sectional community fever survey drawn from the HDSS and Ifakara Town areas $(\mathrm{N}=80)$

2. The longitudinal degedege community study with cases drawn from the longitudinal HDSS surveillance $(\mathrm{N}=129)$

3. Longitudinal shamba fever study in which a random sample of households was followed during the time spent in their shamba $(\mathrm{N}=29)$.

All studies only included children who had experienced either an episode of fever or of degedege in the past 14 days. For ethical reasons, children who had not recovered the day before the interview were excluded from the study, and those who were still sick at the time of the interviewer's visit were advised to attend a health facility. The EMIC was administered to caretakers of the children immediately after finding the case, except for the longitudinal degedege study, in which interviewers visited the household of the child two to four weeks after a HDSS 
Table I: Characteristics of the Three Studies

\begin{tabular}{|c|c|c|c|}
\hline & $\begin{array}{l}\text { Cross-sectional Community fever } \\
\text { survey }\end{array}$ & $\begin{array}{l}\text { Longitudinal degedege } \\
\text { community study }\end{array}$ & Longitudinal shamba (farm sites) fever study \\
\hline Aim of the study & $\begin{array}{l}\text { To examine treatment-seeking } \\
\text { behaviour for fever }\end{array}$ & $\begin{array}{l}\text { To explain treatment-seeking } \\
\text { behaviour for degedege, and } \\
\text { identify how symptoms and } \\
\text { causes related to degedege } \\
\text { effect first response strategies }\end{array}$ & $\begin{array}{l}\text { To examine treatment-seeking for fever during } \\
\text { farming season }\end{array}$ \\
\hline Study setting & HDSS area of Kilombero and Ulanga & $\begin{array}{l}\text { HDSS area of Kilombero and } \\
\text { Ulanga }\end{array}$ & HDSS area of Kilombero and Ulanga \\
\hline Sample size & 80 & 129 & 29 \\
\hline Sampling procedure & $\begin{array}{l}\text { A total number of } 318 \text { households } \\
\text { were random-sampled from the } \\
\text { registered } 16,220 \text { households in the } \\
\text { DSS villages. Only households with at } \\
\text { least one under five years of age child } \\
\text { were included in the study. Of all } 318 \\
\text { households, } 58 \text { under five years of } \\
\text { age households reported a fever } \\
\text { episode in the past I } 4 \text { days. } \\
\text { In Ifakara town, a two stage random } \\
\text { sampling of } 223 \text { households was } \\
\text { performed. Of all } 329 \text { ten-cell } \\
\text { leaders, a random sample of } 35 \text { ten } \\
\text { cell leaders were visited to obtain a } \\
\text { complete list of their ten cells. Six } \\
\text { households per each ten-cell were } \\
\text { randomly sampled. Only } 22 \\
\text { households with children under five } \\
\text { years of age met the selection } \\
\text { criteria. }\end{array}$ & $\begin{array}{l}\text { I } 29 \text { Degedege cases were } \\
\text { continuously extracted from } \\
\text { DSS records between } \\
\text { November } 2004 \text { to March } 2006 \\
\text { and followed up for an EMIC } \\
\text { interview }\end{array}$ & $\begin{array}{l}\text { Ten out of } 25 \text { HDSS villages were randomly } \\
\text { selected. A two stage random sample of } 159 \\
\text { households was drawn in proportion to the } \\
\text { relative size of the village. Altogether } 100 \\
\text { households were eligible, but only } 29 \\
\text { households included children under five years } \\
\text { of age who had recovered from a recent fever } \\
\text { episode. These households were therefore } \\
\text { followed for an EMIC interview on monthly } \\
\text { basis }\end{array}$ \\
\hline Study respondents & $\begin{array}{l}\text { Caretakers of children under five } \\
\text { years of age }\end{array}$ & $\begin{array}{l}\text { Caretakers of children under } \\
\text { five years of age }\end{array}$ & Caretakers of children under five years of age \\
\hline Interviewers & ACCESS and HDSS Staff & ACCESS Staff & ACCESS Staff \\
\hline
\end{tabular}

field worker had identified and reported the illness episode. A caretaker was defined as the parent/guardian who provides the daily essential needs of the child, such as bathing, feeding, clothing, or sending the child to school or to the hospital when sick.

Interviews were conducted in Kiswahili by HDSS field workers and by two trained local interviewers of the ACCESS programme, one doing the interview, a second one recording the answers. All interviews, except those done by the HDSS field workers, were tape-recorded, transcribed and entered into their respective sections in the EMIC. The HDSS interviews were entered directly into the interview questionnaire (EMIC) without being recorded.

For the purpose of adhering to these ethical requirements, all participating individuals who were involved in this project were informed about its aim, the interview procedures, and about their rights as informants before they were asked for their verbal consent. Participation in data collection was voluntary and participants were free to leave at any time.

\section{Sample}

(1) For the HDSS community fever survey, a village stratified random sample was drawn whereby the number of households sampled was proportional to the total number of households in the village. In total, 318 households were drawn from the registered 16,220 households in the DSS villages [30]. Only households with at least one child under five years of age were included in the study. Of all 318 households, 58 reported a fever episode in the past 14 days for a child under five years of age. 
These households were visited between May 2004 and August 2004 for an EMIC interview.

In Ifakara town, there was no updated household list available for sampling purposes. With the support of village and hamlet leaders, the majority of households could be identified and a two-stage random sampling of 223 households performed. Since every household is supposed to be under a ten cell leader a list of all 329 ten cell leaders was established with support from local government officials [30]. A random sample of 35 ten cell leaders was visited for the purpose of setting up a complete list of households within their ten-cells. Six households from each ten cell were then randomly sampled for the study. Only 22 households with children under five years of age met the selection criteria and were visited between May 2004 and August 2004 for an EMIC Interview.

(2) The longitudinal degedege study was conducted between November 2004 and March 2006 in the area of the HDSS. A total number of 129 households whose children had degedege were extracted continuously from DSS records and followed up for an EMIC interview.

(3) For the shamba study, data were collected between January and August 2005, to examine treatment-seeking patterns during the farming season. Ten out of 25 HDSS villages were randomly chosen for the study. A list of villagers $(5,912)$ who had reported to own a farming plot was obtained from HDSS records. A two stage random sample of 159 households was drawn in proportion to the relative size of the village. Altogether 100 households were eligible for the study, but only 29 households had children below five years of age who had recovered from a fever episode. These households (29) were identified and followed to their farming fields on a monthly basis for an EMIC interview.

\section{Data management and analysis}

Quantitative data from the EMIC interviews were doubleentered using Microsoft Fox Pro, and analysed using SAS software (Statistical Analysis of Software Institute, Cary, NC, USA). The analysis was re-computed with reference to illness labels: homa, malaria and degedege. Referring to the national malaria treatment policy, which recommends treatment of malaria within 24 hours of onset of symptoms, children were classified with respect to three outcome variables: (1) 'Timely health facility use' (HF use), defined to include health facility use within 24 hours; (2) 'Timely health facility and anti-malarial use' (HF AM) meaning health facility and anti-malarial use within 24 hours; (3) 'Timely anti-malarial not from the health facility' (AM not HF) refers to children who used timely antimalarial not received from a health facility. The correlation of socio-demographic variables, patterns of distress (illness experiences), and perceived causes (meaning of illness) with the outcome variables were analysed and adjusted in a multivariate logistic regression model.

To clarify the nature of the explanatory model variables and how these explain the outcome variables, the MaxQDA software was used [34]. A coded template for each study was prepared in Microsoft Word, through which qualitative narratives from EMIC interviews were entered before being imported into MaxQDA. Relevant variables were imported from the quantitative data set to select records of particular interest. Content analysis of illness narratives detailed the meaning of categorical codes, and explained the character of correlation identified from quantitative analysis.

\section{Results \\ Sample characteristics}

The socio-demographic characteristics of respondents from the three studies are presented in Table 2. The analysis included 235 children whose caretakers identified the condition as malaria, homa or degedege; three cases that did not fall into any of the above illness labels were excluded. The majority of family caretakers interviewed were women $(82.6 \%)$ and married $(80 \%) .41 .3 \%$ of respondents disclosed that their income is not regular or dependable. The majority (94.9\%) depended on farming as the main source of income and livelihood. Regarding the place of illness recognition, $73.6 \%$ of caretakers recognized the illness of the children at home.

With regard to treatment options for the children, $60.9 \%$ of all children with homa, malaria or degedege were reported to have 'timely health facility' use (HF use). Out of these, $57 \%$ obtained anti-malarial medicines from the facility (HF AM), and 23\% used 'timely anti-malarials not from health facility' (AM not HF) (Table 3).

\section{Treatment-seeking for homa, malaria and degedege}

The demographic characteristics of children in correlation with the outcome variables are presented in Table 3. The sex of the child (female) was associated with less timely health facility use and receipt of anti-malarial medication from the health facility. Being a farmer was also a factor associated with less timely health facility use, but since $95 \%$ of the sample were farmers, this could be expected. It was surprising that health facility availability was associated with timely anti-malarial use not from health facility (AM not HF). This is also reflected in the fact that a lack of immediate use of a health facility was observed among children who reported 'timely used anti-malarials not obtained from health facility'. Illness narratives revealed that health facility availability did not motivate caretakers to seek prompt treatment, since they believed that the health facilities would be out of drug stock. 
Table 2: Demographic Characteristics of Caretaker Respondents (\%)

\begin{tabular}{|c|c|c|c|c|}
\hline & Degedege $n=135$ & Malaria $n=72$ & Homa $\mathrm{n}=28$ & Total $n=235$ \\
\hline \multicolumn{5}{|l|}{ Relationship to the child } \\
\hline Mother & 85.9 & 77.8 & 78.6 & 82.6 \\
\hline Father & 10.4 & 15.3 & 17.9 & 12.8 \\
\hline Grandmother & 0.7 & 4.2 & 0.0 & 1.7 \\
\hline Other & 3.0 & 1.4 & 0.0 & 2.1 \\
\hline Not specified & 0.0 & 1.3 & 3.5 & 0.8 \\
\hline \multicolumn{5}{|l|}{ Marital status } \\
\hline Never married & 9.6 & 13.9 & 10.7 & 11.1 \\
\hline Married & 83.0 & 77.8 & 71.4 & 80.0 \\
\hline Separated, divorced & 5.9 & 8.3 & 14.3 & 7.7 \\
\hline Widowed & 0.7 & 0.0 & 0.0 & 0.4 \\
\hline Not specified & 0.8 & 0.0 & 3.6 & 0.8 \\
\hline \multicolumn{5}{|l|}{ Income } \\
\hline Regular and dependable & 40.0 & 30.6 & 42.9 & 37.4 \\
\hline Possibly & 17.0 & 8.3 & 7.1 & 13.2 \\
\hline Uncertain & 10.4 & 6.9 & 0.0 & 8.1 \\
\hline Not regular and dependable & 32.6 & 54.2 & 50.0 & 41.3 \\
\hline \multicolumn{5}{|l|}{ Occupation } \\
\hline Farmer & 94.8 & 94.4 & 96.4 & 94.9 \\
\hline Trade/Business & 3.7 & 4.2 & 3.6 & 3.8 \\
\hline Labourers & 1.4 & 0.0 & 0.0 & 0.8 \\
\hline Teacher & 0.0 & 1.4 & 0.0 & 0.4 \\
\hline \multicolumn{5}{|l|}{ Illness recognition } \\
\hline Home & 79.3 & 72.2 & 50.0 & 73.6 \\
\hline Shamba & 20.7 & 27.8 & 50.0 & 26.4 \\
\hline
\end{tabular}

Most of the determinants for 'HF use' and 'HF AM' are similar (Table 3). For the categories of distress, 'no interest to play', 'cough' and 'difficult breathing' were associated with timely health facility use and receipt of anti-malarial from the facility (HF AM), while 'hot abdomen' related more to timely health facility use (HF use). For the perceived causes, people stated that 'eating leftover food' and 'stage of child growth' were more associated with 'HF AM' while 'hereditary causes' and 'bird degedege' were associated with less use of 'HF AM'. On the other hand 'blood weakness' was related to 'timely health facility use and receipt of anti-malarial' (HF AM), while those who mentioned 'contamination' as the cause were less likely to use 'timely health facility and receive anti-malarial' (HF AM).

For the outcome variable 'AM not HF', the categories of distress associated with this response included: 'not happy', 'diarrhoea' and 'shivering'. Whereas, the categories of distress of: 'sleeps', 'hot abdomen' and 'froth in mouth' were the symptoms related to less use of timely anti-malarial not from the health facility (AM not HF). The perceived causes related to the same outcome variable were comprised of: breast-feeding and 'do not know the cause', while bird 'degedege' was associated with less use of 'AM not HF'.

\section{Treatment-seeking for degedege}

More specifically, the study narrowed its focus on treatment-seeking patterns for children with degedege (Table 4) compared to homa. For a general fever case definition, the same children had been studied within the ACCESS Programme by Hetzel et al [30], whose interest was to capture the general obstacles to prompt malaria treatment. The present study focuses on how illness experiences and meanings given to degedege influence treatment-seeking patterns.

\section{'Timely health facility use" and "timely health facility and anti-malarial use'}

The study found some similarities in determinants of the outcome variables 'HF use' and 'HF AM' among children with degedege. About $71.1 \%$ of all degedege cases were 'timely brought to health facility' and the majority $(66.7 \%)$ received anti-malarial medication from the facility. In comparison, $45.6 \%$ of children with homa used timely health facility and $42.7 \%$ of them received antimalarial from the facility. Respondents in these groups also mentioned malaria $(\mathrm{p}=0.04)$ and homa $(\mathrm{p}=0.03)$ when talking about the symptoms, indicating that caretakers made a link between convulsions and homa or malaria (Table 4).

Symptoms associated with 'HF AM' included: 'hot abdomen', 'cough', 'no interest to play' and 'difficulty breath- 
Table 3: Demographic and socio-cultural features of children with degedege, malaria and homa $(n=235)$

\begin{tabular}{|c|c|c|c|c|c|c|}
\hline & \multicolumn{2}{|c|}{$\begin{array}{l}\text { HF Use I) } \\
n=143(60.9 \%)\end{array}$} & \multicolumn{2}{|c|}{$\begin{array}{l}\text { HF AM 2) } \\
n=134(57 \%)\end{array}$} & \multicolumn{2}{|c|}{$\begin{array}{l}A M \text { not } \mathrm{HF}^{3)} \\
\mathrm{n}=54(23 \%)\end{array}$} \\
\hline & Estimate & P-Value & Estimate & P-Value & Estimate & P-Value \\
\hline \multicolumn{7}{|l|}{ Demographics } \\
\hline Degedege* & 0.69 & 0.00 & 0.41 & 0.06 & -0.39 & 0.19 \\
\hline $\mathrm{HF}$ availability & & & & & 0.61 & 0.04 \\
\hline HF immediate use (only for AM not HF) & & & & & -1.69 & 0.00 \\
\hline Female Sex & -0.78 & 0.02 & -0.82 & 0.02 & & \\
\hline Never Married & & & & & -1.98 & 0.02 \\
\hline Sep/Div & & & & & -1.14 & 0.21 \\
\hline Farmer & -2.89 & 0.02 & -1.91 & 0.04 & -1.57 & 0.10 \\
\hline \multicolumn{7}{|l|}{ Categories of distress } \\
\hline No interest to play & 0.88 & 0.01 & 0.89 & 0.01 & & \\
\hline Not happy & & & & & 1.41 & 0.03 \\
\hline Sleeps & & & & & -1.29 & 0.00 \\
\hline Loss of appetite & & & -0.24 & 0.16 & -0.42 & 0.09 \\
\hline Crying all the time & -0.37 & 0.15 & & & & \\
\hline Hot body & & & & & 0.28 & 0.07 \\
\hline Hot abdomen & 0.44 & 0.04 & 0.39 & 0.07 & -1.68 & 0.00 \\
\hline Cough & 0.65 & 0.02 & 0.69 & 0.01 & & \\
\hline Difficult breathing & 0.53 & 0.02 & 0.60 & 0.01 & & \\
\hline Yellow eyes & & & & & 0.71 & 0.08 \\
\hline Diarrhoea & 0.29 & 0.07 & & & 0.49 & 0.00 \\
\hline Shivering & & & & & 0.59 & 0.05 \\
\hline Body becomes stiff & 0.39 & 0.05 & 0.33 & 0.09 & & \\
\hline Froth in the mouth & & & & & -1.15 & 0.05 \\
\hline Easily startled & -0.34 & 0.27 & & & & \\
\hline \multicolumn{7}{|l|}{ Perceived causes } \\
\hline Impure water & & & 0.38 & 0.07 & & \\
\hline Eating leftover food & 1.19 & 0.00 & 1.51 & 0.00 & & \\
\hline Breast feeding & & & & & 2.59 & 0.00 \\
\hline Worms & -0.56 & 0.13 & -0.50 & 0.19 & 0.92 & 0.08 \\
\hline Stage of child growth & 0.76 & 0.01 & 0.83 & 0.01 & 0.60 & 0.09 \\
\hline Constitution/blood weakness & 0.77 & 0.13 & 1.14 & 0.03 & & \\
\hline Hereditary & -1.87 & 0.01 & -1.85 & 0.01 & -1.99 & 0.05 \\
\hline Sanitation/dirty environment & & & & & -0.45 & 0.08 \\
\hline Contamination - contact & & & -1.09 & 0.03 & & \\
\hline Wind & & & & & 1.02 & 0.11 \\
\hline Failure to abstain from sex (parent) & -0.91 & 0.13 & -0.75 & 0.16 & $-1.4 \mid$ & 0.06 \\
\hline Bird/insect called degedege & -0.31 & 0.05 & -0.37 & 0.02 & -0.80 & 0.04 \\
\hline Other mention & & & 0.16 & 0.16 & -0.17 & 0.43 \\
\hline Don't know & & & & & 0.94 & 0.01 \\
\hline
\end{tabular}

Note: Model fitness based on the likelihood ratio (all models with $p<0.0001$ )

1) Model outcome: health facility immediate use (HF use) (same day or next day)

2) Model outcome: health facility and antimalarial immediate use (HF AM) (same day or next day)

3) Model outcome: antimalarial immediate use (AM not HF) (same day or next day) not from the health

*illness identified with degedege in the illness narratives even though identified primarily with homa and malaria

ing'. The following narratives indicate how caretakers explain such symptoms and the need to seek prompt treatment: "The child's fever was very high, you know always the fever starts in the abdomen then goes to the head then comes degedege, the only thing is to rush the child to health facility" (female respondent aged 38 from Minepa village). Another caretaker explained, "the child was coughing and struggling hard to breathe like somebody who has asthma, you know the life of any human being depends on breathing so I was scared that the child might die and took him straight to health facility" (female respondent aged 24 from Mngeta village). The patterns of distress that were associated with 'less health facility use' were 'vomiting' and 'increased sleeping'. These symptoms were viewed by caretakers as unserious and manageable in the household, by purchasing drugs from drug stores.

The perceived causes associated with 'HF use' and 'HF AM' were 'blood weakness' and 'sanitation/dirty environment'. The following narratives explain the perceived causes of 
Table 4: Demographic and socio-cultural features of children with degedege $(n=\mid 35)$

\begin{tabular}{|c|c|c|c|c|c|c|}
\hline & \multicolumn{2}{|l|}{$\begin{array}{l}\text { HF Use I) } \\
71.1 \%\end{array}$} & \multicolumn{2}{|l|}{$\begin{array}{l}\text { HF AM 2) } \\
66.7 \%\end{array}$} & \multicolumn{2}{|c|}{$\begin{array}{l}\left.\text { AM not } \mathrm{HF}^{3}\right) \\
10.4 \%\end{array}$} \\
\hline & Estimate & P-Value & Estimate & P-Value & Estimate & P-Value \\
\hline \multicolumn{7}{|l|}{ Demographics } \\
\hline Malaria* & 1.14 & 0.04 & 1.18 & 0.03 & & \\
\hline Homa** & & & 1.44 & 0.03 & & \\
\hline HF availability & & & & & 1.24 & 0.10 \\
\hline Age & & & 0.43 & 0.06 & & \\
\hline \multicolumn{7}{|l|}{ Categories of distress } \\
\hline No interest to play & 1.16 & 0.12 & 2.52 & 0.00 & & \\
\hline Not happy & 1.55 & 0.10 & & & & \\
\hline Sleeps & -1.37 & 0.02 & -1.05 & 0.06 & & \\
\hline No strength & 0.52 & 0.15 & & & & \\
\hline Hot abdomen & 0.79 & 0.02 & 0.56 & 0.05 & & \\
\hline Periodic fevers & & & & & -2.63 & 0.03 \\
\hline Cough & 1.50 & 0.01 & & & 1.56 & 0.06 \\
\hline Difficult breathing & 0.87 & 0.04 & 1.55 & 0.00 & & \\
\hline Diarrhoea & & & 0.55 & 0.14 & 1.50 & 0.02 \\
\hline Vomiting & -0.55 & 0.05 & & & 0.72 & 0.04 \\
\hline Shivering & & & & & 0.78 & 0.09 \\
\hline Twitching & & & & & 1.44 & 0.00 \\
\hline Body becomes stiff & & & 0.42 & 0.09 & & \\
\hline Easily startled & & & & & -5.97 & 0.00 \\
\hline \multicolumn{7}{|l|}{ Perceived causes } \\
\hline Impure water & & & 0.82 & 0.13 & & \\
\hline Starchy food & -2.41 & 0.05 & & & & \\
\hline Stage of child growth & 1.05 & 0.09 & 0.81 & 0.07 & & \\
\hline Constitution/blood weakness & 3.03 & 0.01 & 2.95 & 0.00 & & \\
\hline Sanitation/dirty environment & 1.54 & 0.00 & & & & \\
\hline Personal hygiene/not keeping clean & & & & & 4.19 & 0.01 \\
\hline Cold weather & & & & & 1.39 & 0.05 \\
\hline Spirits & -1.72 & 0.03 & & & & \\
\hline Failure to abstain from sex (parent) & -2.84 & 0.03 & -1.13 & 0.17 & & \\
\hline Bird/insect called degedege & & & -0.60 & 0.00 & & \\
\hline Other mention & & & & & -0.55 & 0.08 \\
\hline
\end{tabular}

Note: Model fitness based on the likelihood ratio (all models with $p<0.000$ I)

1) Model outcome: health facility immediate use (HF use) (same day or next day)

2) Model outcome: health facility and antimalarial immediate use (HF AM) (same day or next day)

3) Model outcome: antimalarial immediate use (AM not HF) (same day or next day) not from the health facility

*Illness identified with malaria in illness narratives even though identified primarily with degedege

** Illness identified with homa in illness narratives even though identified primarily with degedege

degedege by respondents: "Dirty environment around the house like bushes, grasses, pit, and stagnant water are breeding grounds for mosquitoes causing malaria" (male respondent aged 35 from Kichangani village). Some caretakers believe that some children are born with weak blood, and that makes them more vulnerable to various diseases, including malaria. As a respondent had put it: "My child's blood is weak that is why he is prone to many diseases, the only thing I can do is to try and protect her from contacting different diseases otherwise there is nothing I can do" (female respondent aged 40 from Lupiro village).

'Spirits'(mostly referred by respondents as shetani in Kiswahili or witches) and the bird/insect called 'degedege' were the perceived causes of degedege associated with 'less timely use of health facility and receipt of anti-malarial' among degedege children. This reveals that 'traditional beliefs' about the cause of degedege do influence timely treatment-seeking of health facility. However, illness narratives also revealed that caretakers did not see the importance of prompt treatment at health facilities, since they believed that medical facilities were frequently out of medications. The following translation is typical of quotes from respondents on the reasons not to take degedege children to a health facility: "When I saw my child twitching, I went to the drug shop to buy some anti-malarials, I could not go to the health facility since the drugs are always out of stock" (female respondent aged 37 from Iragua village). 
Another respondent said: "You see, it is waste of time going to the dispensary hoping to get some drugs and being told to get them from drug shops; sometimes you are also told to buy some syringes and bring them to the dispensary for injection, so when the child started twitching and becomes stiff, I with my mother rushed the child to the drug shop and got some quinine" (female respondent aged 30 from Mbingu village).

Illness narratives show that caretakers are well informed about the importance of prompt treatment at a health facility, particularly for young children. The knowledge of this had been acquired from various sources, including: MCH (Mother and Child Health) clinics, previous experience with degedege cases, HDSS staff and the extensive social marketing activities in the study area [35]. The following is typical of narratives identifying the sources through which caretakers acquire knowledge about malaria: "I myself know that whenever the child has various symptoms, I have to take her to the dispensary because when we attend the MCH clinic, we are told how to identify malaria symptoms through which we can promptly seek treatment at the dispensary" (female aged 28 from Idete village).

"My child had high fever, his stool was red and the eyes used to go up - you know I lost one of my children with the same symptoms, so this time I decided on my own to take the child to the dispensary because the other child passed away while my grandfather was trying to sponge him with traditional medicines. I did not want something bad to happen to my child, I immediately rushed him to the dispensary, he got some treatment and he was healed" (female respondent aged 34 from Iragua village).

"People from STIFL (Swiss Tropical Institute Field Laboratory, currently known as Ifakara Health Institute) are doing a wonderful job, you see every house has a number, they visit us frequently and educate us about health issues including malaria and the importance of seeking treatment at a health facility" (male respondent aged 46 from Mbingu village).

\section{'Timely anti-malarial, not from the health facility'}

About $10.4 \%$ of children who had degedege used 'AM not HF' compared to $38.8 \%$ of those who had homa. The patterns of distress associated with this category include 'diarrhoea', 'twitching' and 'vomiting'. Typical degedege symptoms were grouped together and included 'twitching', 'stiff body', 'delirium', 'eyes turn white', 'kicking of legs and arms', 'froth in mouth', 'mouth twisted sideways', 'falling down' and 'easily startled'. Yet, 'twitching' was the only typical degedege symptom associated with timely anti-malarial, not from the health facility (Table 4). On the other hand, 'easily startled' was the pattern of distress that has a negative correlation with "timely anti-malarial receipt but not from the health facility" (AM not HF). The perceived causes that were associated with 'timely anti- malarial use not from the health facility' (AM not HF) were 'personal hygiene' and 'cold weather'.

Representative narratives revealed that the major reasons for children with degedege receiving timely anti-malarial without seeking care from health facility include a belief in 'lack of drugs' and 'poor diagnosis at health facility'. 'Lack of money to pay for treatment' was also pointed out as a reason not to attend a health facility. The following narratives indicate how caretakers explained reasons for not attending health facility: "I went straight to buy drugs at drug shop, I can not go to the dispensary since there is no diagnosis there, they do not take your blood to see what you are suffering from, so even the doctor does not know what he is treating" (male respondent aged 41 from Mpofu village). A woman explained: "There is no need to go the dispensary because in the end you will be told to purchase drugs from drug shops since the dispensary is always out of stock" (female respondent aged 21 from Lupiro village). Another caretakers explained: "I did not have money, I have no work that gives me any income, how can I go to the dispensary with only 100 shillings?, I just went to drug shops, still the money was not enough for the drugs " (female respondent aged 18 from Ikule village).

Although some caretakers also used traditional treatment as the first aid for degedege, they recognized the importance of timely modern treatment to cure degedege. The following quote illustrates the experience reported: "When I saw my child twitching, I went to the bush and got some leaves called 'manunganunga', which I used to sponge the child, after few minutes the twitching stopped so I took my child to the drug shop and we got an anti-malarial" (female respondent aged 39 from Mpofu village).

\section{Discussion}

The study examined local understandings and treatment practices of degedege compared to fever for children younger than five years of age, from the perspectives of their caretakers. This study applied an integrated methodology that examined health system, livelihood, as well as cultural epidemiological determinants of behaviour. The strength of this study lies in the fact that it does not only describe "conventional" factors influencing treatmentseeking behaviour for malaria (e.g. socio-economic characteristics), but also elucidates the significance of illness experiences, meanings and resulting treatment-seeking behaviour, in combination with perceptions on health service delivery. A combination of factors explains treatment-seeking behaviour and is hence key for targeted disease control.

Findings from this study provide both parallel and diverse ideas to previous studies about the role of illness experience, and its meaning for treatment practices of degedege 
and fever cases. The link between degedege and malaria, that respondents make, is certainly confirmed in this study, unlike other studies in sub-Saharan Africa, as reviewed by William and Jones [6], and in Tanzania in particular, where the two conditions were perceived as distinct [14-18].

The majority of children with degedege were taken to health facilities in a timely manner $(71.1 \%)$, compared to those who had homa or malaria (45.6\%). The finding confirms the study by de Savigny et al [21] which indicates modern care as the first choice of treatment for $78 \%$ of fatal malaria cases, and that by Ahorlu [22] where 90\% of respondents identified convulsions as severe condition and recognized the need to seek modern treatment. This finding supports that at least in the selected research area there has been a shift in the practices for first treatment of degedege, compared to what has been reported in previous studies for the same area [14-19]. Moreover, the results provide information on the differences between the treatment patterns for fever (homa) and degedege. Fever cases have been reported as resorting more to modern treatment approaches than degedege cases $[15,18]$, while the present study found a higher percentage children with degedege $(71.1 \%)$ than children with fever $(45.6 \%)$ accessing modern treatment. A number of studies have shown that treatment delay for fever/malaria is due to the perception that this illness is a 'normal everyday illness', and thus not a serious one $[7,24,36]$.

While degedege symptoms were regarded as belonging not to the modern treatment field $[14,18]$, this study attests the use of modern treatment for degedege cases. However, these results can also be attributed to the fact that people in the study area have been exposed to multiple health education campaigns since 1970, including the national 'Mtu ni Afya' (meaning "Man is Health") campaign, which provided intensive information about symptoms, causes, treatment and prevention of malaria [13]. Moreover, in 1996, the study area was marketed via the thorough insecticide-treated nets social marketing campaign [17]. That campaign was preceded by a study [17], which revealed that communities did not link malaria with degedege, and as a result these findings were incorporated in the social marketing to correct the knowledge on linkage between the two. On the other hand, accurate knowledge does not essentially translate into appropriate behaviour, since treatment-seeking is also influenced by a number of other factors [37].

Caretakers of children with degedege who did not use health facilities at all, were less driven by local ideas with regard to the importance of traditional treatment as indicated by various studies [7-12,14-18], but instead, by the fact that the health facilities do not always provide ade- quate treatment options, including drugs and proper diagnosis, or that communities lacked the money to pay for treatment, confirming results of a study by Thera [24]. That health facilities are more often used may result from traditional ideas having become less pervasive, or from the fact that in the past there were fewer, or even no health facility options. Yet, the number of health facilities in Tanzania has been comparably high since 1991, when private health facilities were allowed to operate on their own. It is also possible that in areas where a health facility had previously been available, but not used, the association of traditional causes, however valid, was not as influential on behaviour even then.

A number of studies reported delayed health facility attendance and anti-malarial injection for various degedege related symptoms, including eye rolling, body stiffening and foaming at the mouth, which was regarded as fatal and therefore required traditional treatment $[14,18]$. On the contrary, these findings demonstrate that illness experience of degedege did not hinder caretakers to timely approach health facilities and receive anti-malarial medications. Instead, rather symptoms related to homa, including vomiting and increased sleeping, correlated more with less timely use of health facility than degedege. This particular finding corresponds with results presented by Muela [13], who found that for uncomplicated malaria, vomiting was perceived as a sign of relief, rather than a symptom showing an ascending to complicated malaria, and therefore treatment delay was common.

Spirits, the insect 'degedege', and non-abstinence from sex were the perceived causes of degedege, and associated with less timely use of health facility and receipt of anti-malarial. This finding confirms views from previous studies, where degedege was related by respondents to spiritual causes and hence less likely to trigger the use of health facilities [7-12,14-19]. However, these ideas were not so influential as to keep the majority of children with degedege from accessing health facilities and receiving antimalarial medication. More importantly, the so called dirty environment (bushes, grasses, stagnant water) were considered as contributing to breeding sites for mosquitoes, which were recognized as the cause of degedege and accelerated the need for prompt treatment. This confirms a study conducted within the same programme [30], which found that for fever and degedege cases, mosquito bites were the most cited perceived cause.

More generally, the findings indicate that symptoms rather than causes are now the drivers of health-seeking behaviour. This may at least partly be attributed to the many health interventions and campaigns carried out in the study area emphasizing the importance of recognizing and responding to danger symptoms. The present study 
took place two years after the 2002 introduction of IMCI (Integrated Management of Childhood Illnesses) devoting training to caregivers on early recognition of dangerous symptoms among children, through which prompt treatment at health facility was highly suggested [38]. The social marketing of insecticide treated nets (KINET) and of prompt and appropriate treatment seeking (ACCESS) program have certainly also contributed.

However it is important to point out that the results of the study are context-based and cannot be generalized. Firstly, the sample size of the study was restricted since it focused on first treatment and was based only on reported fever and degedege cases. Secondly, the study site was influenced by extensive malaria research activities and interventions that have been taking place in Kilombero and Ulanga Districts since several decades. While the results might not reflect the situation in other parts of the country, they provide insights into the effects of interventions such as the ACCESS programme in this area, and may thus inform research, policy and practice.

\section{Conclusion}

This study examined caretakers' treatment-seeking patterns for children with degedege and homa, and then compared the findings with results from previous studies focusing on the same theme. Findings suggest that intensive community health education on causes and danger symptoms can trigger seeking of appropriate and timely treatment, and had positive influence on changed healthseeking behaviour in the study area. Health facility use was even higher among degedege children compared to children with normal fever. Furthermore, findings revealed that traditional ideas are no longer a significant influence in delaying health facility use for children with degedege. Even for children with degedege who did not use a health facility at all, reasons associated with this had more to do with poor services in the respective facility, and/or lack of money to pay for consultation and/or treatment, than the belief that degedege is better managed by traditional practices.

The main reasons why services were considered as inadequate were a lack of drugs and competence as well as equipment to make accurate diagnosis. Communities are exposed to insecurities when they lack financial capital, a significant livelihood asset in seeking care, especially when the exemption of children under the age of five who are supposed to receive free treatment in health facilities is not effective [30]. In order to further encourage people to seek timely and appropriate treatment, quality of care at health facilities needs to be improved, through making diagnosis and provider compliance with treatment guidelines more accurate, as well as therapies including drugs more available and affordable to communities. Initiatives for strengthening livelihoods including economic capabilities are also relevant in ensuring prompt and timely malaria treatment. Moreover, further education needs to focus on proper causes of malaria, specifically to correct the inaccurate association of malaria with degedege bird and hereditary causes. Finally, the correlation between female children and less use of timely health facility certainly needs to be explored in more depth since this may reflect a gender bias with regard to early treatment.

\section{Competing interests}

The authors declare that they have no competing interests.

\section{Authors' contributions}

$\mathrm{AD}$ was involved in the design and implementation of the study, field work, data management, analysis, interpretation and writing of the manuscript. AS, BO, CL, HM conceived the programme and its components, provided technical support and supervision, and commented on the manuscript. MW was involved in the design and analysis of the EMIC, interpretation and discussion of the findings. $\mathrm{BO}$ was involved in the conception and design of the study, data analysis, interpretation and writing of this paper. CP was involved in data analysis, interpretation and writing of this paper. $\mathrm{MH}$ was involved in the design and implementation of the studies and IM contributed to data collection and discussion of the findings. DG was in charge of statistical support and contributed to the analysis of the data. FK, AM and CM were responsible for the development and implementation of the interventions. All authors have read and approved the final manuscript.

\section{Ethical review}

This paper was published with the permission of Dr. Andrew Kitua, Director General, National Institute for Medical Research. Ethical Clearance of the ACCESS Programme proposal was granted by the National Institute for Medical Research of the United Republic of Tanzania (NIMR/HQ/R.8a/Vol.IX/236, September 16, 2003).

\section{Acknowledgements}

The authors wish to thank the communities of Kilombero and Ulanga Districts and their leaders for their active participation in the study. Special thanks to ACCESS and DSS field workers for their work commitment. We are grateful to IHI Data Unit and Hilda Mwambukusi who entered the questionnaires. We sincerely appreciate the contribution of Sandra Alba in statistical analysis of the data. Funding for this research was provided by Novartis Foundation for Sustainable Development and the Scholarship Programme of Basel City for Students from Developing Countries.

\section{References}

I. WHO/HTM/GMP: World Malaria Report Geneva: WHO; 2008.

2. Ministry of Health: National Guidelines for Malaria Diagnosis and Treatment Dodoma: Government of the United Republic of Tanzania; 2000.

3. Gomes F, Faiz MA, Gyapong JO, Warsame M, Agbenyega T, Babiker A, Baiden F, Yunus EB, Binka F, Clerk C, Folb P, Hassan R, Hossain MA, Kimbute O, Kitua A, Krishna S, Makasi C, Mensah N, Mrango Z, Olliaro P, Peto R, Peto TJ, Rahman MR, Ribeiro J, Samad R, White NJ: 
Pre-referral rectal artesunate to prevent death and disability in severe malaria: a placebo-controlled trial. Lancet. 2008, 373(9663):557-566.

4. Hetzel MW, Iteba N, Makemba AM, Mshana C, Lengeler L, Obrist B, Schulze A, Nathan R, Dillip A, Alba S, Mayumana I, Khatib RA, Njau $\mathrm{JD}$, Mshinda $\mathrm{H}$ : Understanding and Improving access to prompt and effective malaria treatment and care in rural Tanzania: the ACCESS Programme. Malar J 2007, 6:83.

5. WHO: Severe falciparum malaria. Trans $R$ Soc of Trop Med Hyg 2000, 94(Suppl I): I-90.

6. Williams $\mathrm{HA}$, Jones $\mathrm{COH}$ : A critical review of behavioral issues related to malaria control in sub-Saharan Africa: what contributions have social scientists made? Soc Sci Med 2004, 59:501-523.

7. Mwenesi H, Harpham T, Snow RW: Child malaria treatment practices among mothers in Kenya. Soc Sci Med 1995, 40: $127 \mid-1277$.

8. Beiersman C, Sanou A, Wladarsch E, De Allegri M, Kouyate B, Muller O Malaria in rural Burkina Faso: Local illness concepts, patterns of traditional treatment and influence on health seeking behaviour. Malar J 2007, 6:106.

9. Adongo BP, Kirkwood B, Kendal C: How local community knowledge about malaria affects insecticide-treated net use in northern Ghana. Trop Med Int Health 2005, I 0:366-378.

10. Hill Z, Kendal C, Arthur P, Kirkwood B, Adjei E: Recognizing childhood illnesses and their traditional explanations: exploring options for care seeking interventions in the context of IMCI strategy in rural Ghana. Trop Med Int Health 2003, 8:668-676.

II. Snow RW, Mwenesi H, Rapuoda B: Malaria situation analysis for Kenya. Technical Report prepared for the Department for International Development London: Department for International Development; 1998.

12. Ahorlu CK, Dunyo SK, Afari EA, Koram KA, Nkurumah FK: Malaria related beliefs and behaviour in Southern Ghana: Implication for treatment, prevention and control. Trop Med Int Health 1997, 2:488-499.

13. Hausman-Muela S: Community understanding of malaria, and treatment seeking behaviour, in a holoendemic area of southeastern Tanzania. In PhD thesis University of Basel: Swiss Tropical Institute; 2000.

14. Comoro C, Nsimba SED, Warsame M, Tomson G: Local understanding, perception and reported practices of mothers/ guardians and health workers on childhood malaria in a Tanzania district-implications for malaria control. Acta Trop 2003, 87:305-3I3.

15. Makemba AM, Winch PJ, Makame VM, Mehl GL, Premji Z, Minjas JN, Shiff CJ: Treatment practices for degedege, a locally recognized febrile illness, and implications for strategies to decrease mortality from severe malaria in Bagamoyo District, Tanzania. Trop Med Int Health 1996, I:305-313.

16. Mayombana C: Local understanding and practices related to IMCI interventions in Eastern Tanzania. In PhD thesis University of Basel: Swiss Tropical Institute; 2004.

17. Minja H, Schellenberg JA, Mukasa O, Nathan R, Abdulla S, Mponda H, Tanner M, Lengeler C, Obrist B: Introducing insecticide-treated mosquito nets in the Kilombero Valley, Tanzania: the relevance of local knowledge and practices for an information, education and communication (IEC) campaign. Trop Med Int Health 2001, 6:614-23.

18. Winch PJ, Makemba AM, Kamazima SR, Lurie M, Lwihula GK, Premji Z, Minjas JN, Shiff CJ: Local terminology for febrile illnesses in Bagamoyo District, Tanzania and its impact on the design of a community-based malaria control programme. Soc Sci Med 1996, 42:1057-1067.

19. Warsame M, Kimbute O, Machinda Z, Ruddy P, Melksedick M, Peto T, Ribeiro I, Kitua A, Tomson G, Gomes M: Recognition, perceptions and treatment practices for severe malaria in rural Tanzania: implication for accessing rectal artesunate as a pre-referral. PLOS ONE 2007, 2:el49.

20. Makundi EA, Malebo HM, Mhame P, Kitua AY, Warsame M: Role of traditional healers in the management of severe malaria among children below five years of age: the case of Kilosa and Handeni districts, Tanzania. Malar J 2006, 5:58.

21. De Savigny D, Mayombana C, Mwangeni E, Masanja H, Minhaj A, Mkilindi Y, Mbuya C, Kasele H, Reis G: Care-seeking patterns for fatal malaria in Tanzania. Malar J 2004, 3:27.
22. Ahorlu CK, Koram KA, Ahorlu C, de Savigny D, Weiss MG: Community concepts of malaria-related illness with and without convulsions in southern Ghana. Malar J 2005, 4:47.

23. Kazembe LN, Appleton CC, Kleinschmidt I: Choices of treatment for fever at household level in Malawi: examining spatial patterns. Malar J 2007, 6:40.

24. Thera MA, D'Alessandro U, Thiero M, Ouedraogo A, Packou J, Souleymanne OAD, Fane M, Ade G, Alvez F, Doumbo O: Child malaria Treatment practices among mothers in the district of Yanfolila, Sikasso region, Mali. Trop Med Int Health 2000, I 2:876-88I.

25. Asenso-Okyere WK, Dzator JA: Household costs of seeking malaria care. A retrospective study of two districts in Ghana. Soc Sci Med 1997, 45:659-667.

26. Ensor T, Cooper S: Overcoming barriers to health services access: Influencing the demand side. Health Policy Plan. 2006, I9(2):69-79.

27. Gulliford M, Figueroa-Munoz J, Morgan M, Hughes D, Gibson B, et al: What does 'Access to Health Care' mean? J Health Serv Res Policy 2002, 7:186-188.

28. Andersen RM: Revisiting the behavioral model and access to medical care: Does it matter? J Health Soc Behav 1995, 36: I- 10.

29. Obrist B, Iteba N, Lengeler C, Makemba A, Mshana C, Mshinda H, Nathan R, Alba S, Dillip A, Hetzel MW, Mayumana I, Schulze A: Access to Health Care in Contexts of Livelihood Insecurity: A Framework for Analysis and Action. PLoS Med. 2007, 4(I0): I584- I588

30. Hetzel MW, Obrist B, Lengeler L, Msechu J, Nathan R, Dillip A, Makemba AM, Mshana C, Schulze A, Mshinda H: Obstacles to prompt and effective malaria treatment lead to low community-coverage into two rural districts of Tanzania. BMC Public Health 2008, 8:317.

31. United Republic of Tanzania: 2002 Population and Housing Census 2003 [http://www.tanzania.go.tz/census/index.html].

32. Hetzel MW, Alba S, Frankhauser M, Mayumana I, Lengeler L, Obrist B, Nathan R, Msechu J, Nathan R, Makemba AM, Mshana C, Schulze $A$, Mshinda $H$ : Malaria risk and access to prevention and treatment in the paddies of the Kilombero Valley, Tanzania. Malar J 2008, 7:7.

33. Weiss MG: Framework for comparative study of illness. Transcultural Psychiatry 1997, 34:235-263.

34. Max: Qualitative Data Analysis Introduction Verbi Software 2001 [http://www.maxqda.com].

35. Armstrong Schellenberg JRM, Abdulla S, Minja H, Nathan R, Mukasa O, Marchant T, Mponda H, Kikumbih N, Lyimo E, Manchester T, Tanner M, Lengeler C: KINET: A Social Marketing Programme of Treated Nets and Net Treatment for Malaria Control in Tanzania, with Evaluation of Child Health and Long-term Survival. Trans R Soc Trop Med Hyg 1999, 93:225-23I.

36. Kamat VR: "I thought it was only ordinary fever!" cultural knowledge and the micropolitics of therapy seeking for childhood febrile illness in Tanzania. Soc Sci Med 2006, 62:2945-2959.

37. Hausman-Muela S, Ribera MJ, Mushi AK, Tanner M: Medical syncretism with reference to malaria in a Tanzanian community. Soc Sci Med 2002, 55:403-4I3.

38. Armstrong Schellenberg JRM, Bryce J, de Savigny D, Lambrechts T, Mbuya C, Mgalula L, Wilczynska K: The effect of Integrated Management of Childhood Illness on observed quality of care of under-fives in rural Tanzania. Health Policy Plan 2004, 19:1-10.

Publish with Bio Med Central and every scientist can read your work free of charge

"BioMed Central will be the most significant development for disseminating the results of biomedical research in our lifetime. "

Sir Paul Nurse, Cancer Research UK

Your research papers will be:

- available free of charge to the entire biomedical community

- peer reviewed and published immediately upon acceptance

- cited in PubMed and archived on PubMed Central

- yours - you keep the copyright
BiolMedcentral 